\title{
Production Facility Layout Design Using Activity Relationship Chart (ARC) And From To Chart (FTC) Methods
}

\section{Perancangan Tata Letak Fasilitas Produksi Dengan Menggunakan Metode Activity Relationship Chart (ARC) Dan From To Chart (FTC)}

\author{
Ata Barbara ${ }^{1}$, Atikha Sidhi Cahyana ${ }^{2}$ \\ \{atabarbara26@gmail.com¹ ${ }^{1}$ atikhasidhi@umsida.ac.id ${ }^{2}$ \} \\ ${ }^{1,2}$ Program Studi Teknik Industri, Fakultas Sains dan Teknologi, Universitas \\ Muhammadiyah Sidoarjo
}

\begin{abstract}
PT. XYZ is a company engaged in the field of transformers which produces several types of transformers. Transformer production process is made to order a production process that has a fluctuating pattern. Companies also often cannot estimate the number of transformers that will be produced to meet consumer demand.

The purpose of this study is to improve plant layout with an efficient layout. One method used in this study is the Activity Relationship Chart and From To Chart methods. Activity Relationship Chart and From To Chart are methods that can help solve problems which are then explained in more detail through several stages of completion to the optimal point. This research is expected to produce a more efficient layout using the Activity Relationship Chart and From To Chart method.
\end{abstract}

Keywords : facility layout, activity relashionship chart, from to chart

Abstrak. PT. XYZ merupakan perusahaan yang bergerak dibidang transformers yang memproduksi beberapa jenis trafo. Proses produksi trafo merupakan proses produksi make to order yang memiliki pola fluktuatif. Perusahaan juga sering kali tidak dapat memperkirakan jumlah trafo yang akan diproduksi untuk memenuhi permintaan konsumen. Tujuan dari penelitian ini yaitu memperbaiki layout pabrik dengan biaya yang optimum. Salah satu metode yang digunakan dalam penelitian ini adalah metode Activity Relationship Chart dan From To Chart. Activity Relationship Chart dan From To Chart merupakan metode yang dapat membantu untuk penyelesaian persoalan-persoalan yang kemudian diuraikan secara lebih rinci dengan melalu beberapa tahap penyelesaian sampai pada titik yang optimum. Dari penelitian ini dapat menghasilkan layout yang lebih efisien dengan menggunakan metode Activity Relationship Chart dan From To Chart. Sehingga proses produski menjadi lebih efisien dari segi jarak antar departemen dan lebih murah dari segi biaya material handling.

Kata Kunc i: tata letak fasilitas, activity relashionship chart, from to chart

\section{Pendahuluan}

PT. XYZ adalah perusahaan yang bergerak di bidang transformer pembuatan trafo distribusi dan trafo power. Trafo distribusi yang dihasilkan memiliki daya paling tinggi sebesar $275 \mathrm{Kv}$, sementara trafo power memiliki daya paling tinggi sebesar 166.7 MVA. Trafo distribusi yang diproduksi dipasang diatas tiang listrik dan untuk trafo power dipasang pada gardu-gardu yang berada di PLN. Ada 9 jalur produksi atau stasiun kerja yang memiliki fungsi masing-masing.

Perubahan material dari tempat satu ketempat lain yang biasa disebut dengan istilah material handling dapat meminimalisir biaya menjadi lebih efisien. Material yang dipindahkan pasti memiliki alasan dan tujuan tertentu. Dapat bergerak secara efisien atau tidaknya suatu material dapat ditentukan dengan system material handling. Namun pada segi biaya material handling ini memiliki proporsi biaya yang cukup besar.

Di PT. Bambang Djaja memiliki 9 jalur atau setasiun kerja. Jalur A yaitu untuk proses Coil, jalur B untuk proses Core, jalur $\mathrm{C}$ untuk proses Oven, jalur D untuk proses Tanking, jalur E untuk proses Final Assembly, jalur $\mathrm{F}$ untuk proses Testing, jalur G Leak Test (Brazing \& Painting), jalur H Logistik, dan yang terakhir jalur I bagian Parking Area Transformer.

\section{METODE}


Metode yang digunakan dalam skripsi ini adalah metode activity relationship chart and from to chart. ARC merupakan teknik yang menggunakan derajat hubungan aktivitas di dalam merencanakan tata letak fasilitas atau departmen. Sering dikaitkan dalam penilaian kualitatif dan cenderung berdasarkan pertimbangan yang bersifat subjective dari masing-masing fasilitas (Pratiwi, 2015).

FTC merupakan diagram yang digunakan untuk menunjukkan alian material dari satu departemen kedepartemen lainnya. Adapun data yang diambil adalah data primer dan data sekunder.

1. Data Primer yang meliputi : Layout awal produksi, luas dan jarak antar department produksi dan frekuensi perpindahan material.

2. Data Sekunder yang meliputi : Uraian proses produksi dan volume produksi.

\section{HASIL DAN PEMBahasan}

\section{Luas Area Produksi}

Luas lantai produksi digunakan untuk mencari luas total dari ruang produksi yang dibutuhkan untuk sebuah proses produksi. Produksi trafo memerlukan banyak proses yang cukup panjang. Dari beberapa departemen yang di sebutkan diatas yang memiliki luas paling besar adalah departemen coil seluas 912 meter karena departemen tersebut menangani beberapa jalur produksi. Departemen yang memiliki luas hampir mirip nantinya akan mengalami perubahan.

\section{Jarak Antar Departemen}

Jarak antar departemen yang jauh akan menyebabkan proses produksi tidak efektif. Pada jarak antar departemen diatas yang memiliki jarak paling jauh adalah departemen logistik sebesar 49 meter. Jarak departemen lainya relatif lebih dekat. Jarak departemen bisa dirubah dengan memindah atau mendesain ulang layout produksi.

Tabel 1. Alur Proses Produksi

\begin{tabular}{|c|c|c|c|c|c|c|c|c|c|c|}
\hline \multicolumn{11}{|c|}{ Departemen Produksi } \\
\hline $\begin{array}{c}\text { Gudang } \\
\text { Bahan } \\
\text { Baku }\end{array}$ & A & B & c & D & E & F & G & H & I & $\begin{array}{l}\text { Product } \\
\text { Jadi }\end{array}$ \\
\hline 1 & Coil & Core & Oven & Tanking & $\begin{array}{l}\text { Final } \\
\text { Assembly } \\
5\end{array}$ & Testing & Leak Test & Logistik & $\begin{array}{l}\text { Parking area } \\
\text { Transformer }\end{array}$ & ? \\
\hline & & & & & & & & & & \\
\hline
\end{tabular}

\section{Activity Relationship Chart}

Activity Relationship Chart (ARC) adalah sebuah metode yang digunakan untuk menentukan besar kecilnya nilai keterkaitan dari masing-masing departemen terhadap departemen lainya.

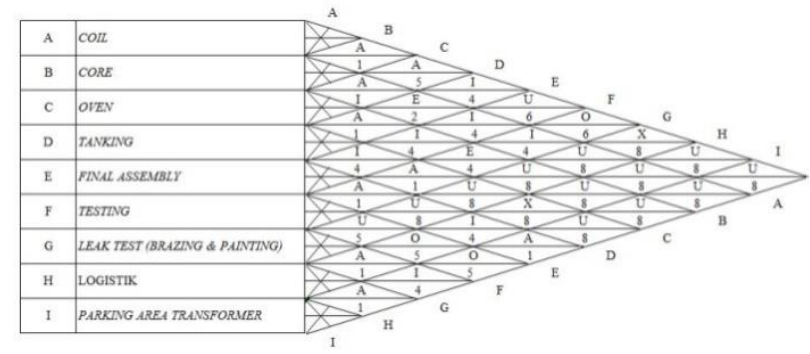

Gambar 1. Activity Reliationship Chart Jalur Produksi Trafo

Berdasarkan derajat hubungan antar aktivitas dan alasannya, maka ARC untuk 9 departmem pada PT. XYZ terdapat pada gambar 1. Pada ARC telah digambarkan hubungan keterkaitan antar pasangan fasilitas-fasilitas yang ada dilengkapi dengan derajat kedekatan A, E, I, O, U dan X beserta alasannya.

Tabel 2. Alur Proses Produksi 
Procedia of Engineering and Life Science Vol. 1. No. 2 Juni 2021

Seminar Nasional \& Call Paper Fakultas Sains dan Teknologi (SENASAINS 2nd)

Universitas Muhammadiyah Sidoarjo

\begin{tabular}{|c|l|c|l|}
\hline \multicolumn{5}{|c|}{ Derajat Haubungan } \\
\hline Nilai & \multicolumn{1}{|c|}{ Diskripsi } & Kode Garis & Kode Warna \\
\hline A & Mutlak perlu didekatkan & $\overline{\text { M }}$ & Merah \\
\hline E & Sangat penting untuk didekatkan & $\overline{ }$ & Orange \\
\hline I & Penting untuk didekatkan & $\overline{ }$ & Hijau \\
\hline O & Cukup/biasa & & Biru \\
\hline U & Tidakpenting & & Tanpa warna \\
\hline X & Tidak dikehendaki berdekatan & M & Coklat \\
\hline
\end{tabular}

Pada tabel Total Closeness Rating menunjukkan bahwa departemen pertama untuk diletakkan pada tempat yang strategis dan dapat dijangkau oleh departemeen lainnya adalah departemen Testing (F). Untuk peletakkan kedua dan seterusnya mengikuti urutan dari tabel Total Closeness Rating hingga akhir menjadi sebuah layout terbaik sesuai dengan algoritma tersebut.

Tabel 3. Total Closeness Rating

\begin{tabular}{|c|c|c|c|c|c|c|c|c|c|c|c|}
\hline & \multicolumn{10}{|c|}{ Departemen } \\
\hline Departemen & A & B & C & D & E & F & G & H & I & Total & Order \\
\hline A & - & A & A & I & U & O & X & U & U & 18 & 8 \\
\hline B & A & - & A & E & I & I & X & U & U & 22 & 4 \\
\hline C & A & A & - & A & I & E & X & U & U & 24 & 3 \\
\hline D & I & E & A & - & I & A & X & X & U & 21 & 5 \\
\hline E & U & I & I & I & - & A & U & I & A & 24 & 2 \\
\hline F & O & I & E & A & A & - & U & O & O & 24 & 1 \\
\hline G & X & U & U & U & U & U & - & A & I & 13 & 9 \\
\hline H & U & U & U & X & I & O & A & - & A & 18 & 7 \\
\hline I & U & U & U & U & A & O & I & A & - & 19 & 6 \\
\hline Total & 18 & 22 & 24 & 21 & 24 & 24 & 13 & 18 & 19 & & \\
\hline Order & 8 & 4 & 3 & 5 & 2 & 1 & 9 & 7 & 6 & & \\
\hline
\end{tabular}

\section{Kombinasi Garis}

Kombinasi garis untuk derajat hubungan ini merupakan ilustrasi dari Activity Relationship Chart yang telah ditentukan. Kombinasi garis mengikuti aturan dan simbol dari Activity Relationship Chart. Misalkan kode A maka garisnya berjumlah empat garis dan berwarna merah, begitupun dengan kode-kode selanjutnya.

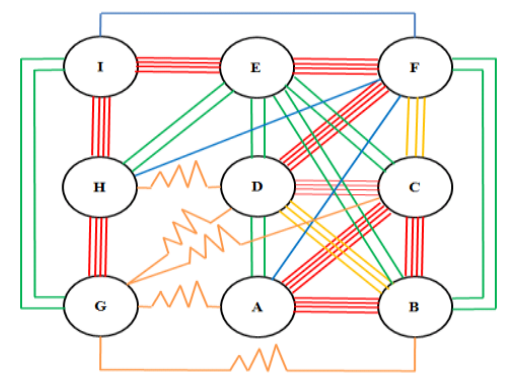


Gambar 2. Kombinasi Garis Jalur Produksi Trafo

Pada gambar garis kombinasi diatas terlihat departemen $\mathrm{C}$ atau Oven yang paling penting untuk didekatkan dengan departemen lain. Total ada 5 departemen yang perlu didekatkan dengan departemen tersebut agar departemen produksi lebih efisien. Alur produksi pembuatan trafo adalah dimulai dari departemen A ke B lalu membentuk huruf U hingga departemen D, kemudian departemen D melanjutkan ke F, kemudian departemen $\mathrm{F}$ ke $\mathrm{G}$ lalu membentuk huruf L. Proses produksi dan penataan departemen pada layout juga harus memperhatikan kondisi sebenarnya dilapangan.

\section{FTC Berdasarkam Perhitungan Ongkos Material Handling (OMH)}

From to chart merupakan diagram yang digunakan untuk menunjukkan alian material dari satu departemen kedepartemen lainnya. Prinsip yang diterapkan didalam analisa aliran material dengan menggunakan From To Chart ini adalah mencoba mencari material handling seminimal mungkin. Perhitungan jarak perpindahan material handling menggunakan ketentuan ukur jarak Aisle Distance, dimana pengukuran jarak ini merupakan pengukuran jarak secara aktual dengan mengukur jarak sepanjang lintasan yang dilalui alat pengangkut bahan atau material handling

Tabel 4. Luas Area Produksi Pada Layout Usulan

\begin{tabular}{|c|c|l|c|l|}
\hline No & Kode & Work Station/Departemen & Luas Lantai & Satuan \\
\hline 1 & A & Coil & 915 & $\mathrm{~m}^{2}$ \\
\hline 2 & B & Core & 650 & $\mathrm{~m}^{2}$ \\
\hline 3 & C & Oven & 280 & $\mathrm{~m}^{2}$ \\
\hline 4 & D & Tanking & 160 & $\mathrm{~m}^{2}$ \\
\hline 5 & E & Final Assembly & 600 & $\mathrm{~m}^{2}$ \\
\hline 6 & F & Testing & 450 & $\mathrm{~m}^{2}$ \\
\hline 7 & G & Leak Test (Brazing \& Painting) & 280 & $\mathrm{~m}^{2}$ \\
\hline 8 & H & Logistik & 150 & $\mathrm{~m}^{2}$ \\
\hline 9 & I & Parking Area Transformer & 230 & $\mathrm{~m}^{2}$ \\
\hline
\end{tabular}

Tabel 5. Jarak Perpindahan Material Handling Pada Layout Usulan

\begin{tabular}{|c|c|c|c|c|c|c|c|c|c|c|}
\hline \multirow[b]{2}{*}{$\mathrm{Ke}$} & \multirow[b]{2}{*}{ Dari } & $\begin{array}{c}\mathrm{SK} \\
1\end{array}$ & $\begin{array}{l}\mathrm{SK} \\
2\end{array}$ & SK 3 & SK 4 & SK 5 & SK 6 & SK 7 & SK 8 & SK 9 \\
\hline & & Coil & Core & Oven & Tanking & $\begin{array}{c}\text { Final } \\
\text { Assembly }\end{array}$ & Testing & $\begin{array}{c}\text { Leak } \\
\text { Test } \\
\text { (Brazing } \\
\& \\
\text { Painting) }\end{array}$ & Iogistik & $\begin{array}{c}\text { Parking } \\
\text { Area } \\
\text { Transformer }\end{array}$ \\
\hline $\begin{array}{c}\mathrm{SK} \\
1\end{array}$ & Coil & & 10 & 50 & 36 & 40 & 66 & 57 & 30 & $5 \overline{5}$ \\
\hline $\begin{array}{c}\mathrm{SK} \\
2\end{array}$ & Core & 10 & & 40 & 25 & 25 & 20 & 10 & 10 & 35 \\
\hline $\begin{array}{c}\mathrm{SK} \\
3\end{array}$ & Oven & 50 & 40 & & 15 & 20 & 40 & 48 & 34 & 60 \\
\hline $\begin{array}{c}\text { SK } \\
4\end{array}$ & Tanking & 36 & 25 & 15 & & 5 & 25 & 30 & 22 & 37 \\
\hline $\begin{array}{c}\mathrm{SK} \\
5\end{array}$ & $\begin{array}{l}\text { Final } \\
\text { Assembly }\end{array}$ & 40 & 25 & 20 & 5 & & 15 & 15 & 28 & 30 \\
\hline $\begin{array}{c}\text { SK } \\
6\end{array}$ & Testing & 66 & 20 & 40 & 25 & & & 42 & 37 & 20 \\
\hline$\stackrel{\mathrm{SK}}{7}$ & $\begin{array}{l}\text { Leak Test } \\
\text { (Brazing \& } \\
\text { Painting) }\end{array}$ & 57 & 10 & 48 & 30 & & 42 & & 25 & 20 \\
\hline $\begin{array}{c}\mathrm{SK} \\
8\end{array}$ & Logistik & 30 & 10 & 34 & 22 & & 37 & 25 & & 10 \\
\hline $\begin{array}{c}\mathrm{SK} \\
9\end{array}$ & $\begin{array}{l}\text { Parking } \\
\text { Area } \\
\text { Transformer }\end{array}$ & ธิธ & 35 & 60 & 37 & & 20 & 20 & 10 & \\
\hline
\end{tabular}


Procedia of Engineering and Life Science Vol. 1. No. 2 Juni 2021

Seminar Nasional \& Call Paper Fakultas Sains dan Teknologi (SENASAINS 2nd)

Universitas Muhammadiyah Sidoarjo

\begin{tabular}{|c|c|l|c|l|}
\hline No & Kode & Work Station/Departemen & Luas Lantai & Satuan \\
\hline 1 & A & Coil & 915 & $\mathrm{~m}^{2}$ \\
\hline 2 & B & Core & 650 & $\mathrm{~m}^{2}$ \\
\hline 3 & C & Oven & 280 & $\mathrm{~m}^{2}$ \\
\hline 4 & D & Tanking & 160 & $\mathrm{~m}^{2}$ \\
\hline 5 & E & Final Assembly & 600 & $\mathrm{~m}^{2}$ \\
\hline 6 & F & Testing & 450 & $\mathrm{~m}^{2}$ \\
\hline 7 & G & Leak Test (Brazing \& Painting) & 280 & $\mathrm{~m}^{2}$ \\
\hline 8 & H & Logistik & 150 & $\mathrm{~m}^{2}$ \\
\hline 9 & I & Parking Area Transformer & 230 & $\mathrm{~m}^{2}$ \\
\hline
\end{tabular}

Darı tabel dıatas menunjukkan ada pengembalıan handlıng yaitu dı D ke B, dı F ke D, di H ke G, dan I ke $\mathrm{H}$ yang seharusnya dihindari dengan total keseluruhan adalah 341 meter dengan biaya/ongkos material handling adalah inflow 2196,061 dan outflow 2160,486. Dengan demikian perlu adanya perubahan tata letak departemen tersebut,

Tabel 7. From To Chart Akhir

\begin{tabular}{|c|c|c|c|c|c|c|c|c|c|c|c|c|}
\hline $\begin{array}{c}\text { TO } \\
\text { FROM }\end{array}$ & A & B & C & D & E & F & G & H & I & TOTAL & Inflow & $\begin{array}{c}\text { Out } \\
\text { Flow }\end{array}$ \\
\hline A & & 10 & & & & & & & & 10 & 555.860 & 533.626 \\
\hline B & & & 40 & & & & & & & 40 & 149.789 & 149.789 \\
\hline C & & & & 15 & & & & & & 15 & 280.86 & 280.86 \\
\hline D & & & & & 30 & & & & & 30 & 133.406 & 133.406 \\
\hline E & & & & & 30 & & & & 30 & 133.406 & 133.406 \\
\hline F & & & & & & 15 & & & 15 & 66.703 & 66.703 \\
\hline G & & & & & & & 15 & & 15 & 66.703 & 66.703 \\
\hline H & & & & & & & & & 42 & 42 & 186.769 & 186.769 \\
\hline I & & & & & & & & & 0 & & \\
\hline TOTAL & 0 & 10 & 40 & 15 & 30 & 30 & 15 & 15 & 42 & 197 & 157 \\
\hline
\end{tabular}




\section{KESIMPULAN}

Dari hasil penelitian dengan menggunakan Activity Relationship Chart berdasarkan alur proses produksi pada tabel 1, menghasilkan departemen mana sajakah yang memang harus didekatkan seperti pada gambar 6 beserta diagram garis pada gambar 2 penjelasannya. Yang mana, departemen $\mathrm{F}$ atau testing yang paling penting untuk didekatkan dengan 4 departemen disekitarnya yaitu departemen B (core), departemen C (oven), departemen D (tanking), dan departemen E (final).

Dari perhitungan from to chart pada tabel menunjukan bahwa total alur proses handling material ada pengembalian ke departemen sebelumnya yaitu dengan total keseluruhan 341 meter, detelah diperbaiki from to chart pada tabel 7 menunjukan hasil yang efisien yaitu menjadi total keseluruhan 197 meter dengan persentase turun $57,78 \%$.

Dengan demikian perubahan layout akhir dapat mempermudah akses laju proses produksi dengan lebih efektif dan efisien, dengan nilai efisiensi yaitu dari perhitungan from to chart adalah berkurang 57,78\%. Berikut adalah layout usulan seperti pada gambar berikut ini.

\section{REFERENSI}

[1] Nur, Muhamad Iskandar. Igna, Saffrina Fahmi. "Perancangan Tata Letak Fasilitas Ulang (Relayuot) Untuk Produksi Truk Di Gedung Commercial Vehicle (CV) PT. Mercedes Benz Indonesia”. Jurnal Pasti Vol.XI No.1 hal: 66-75.

[2] Nadia, Dini S. Zainal, Ilmi. M Amin, Kadafi. 2017. “ Analisis Perancangan Tata Letak Fasilitas Produksi Menggunakan Metode Activity Relationship Chart (ARC)”. Jurnal Manajemen Vol.9 No.1 hal: 38-47.

[3] Jamalludin, A. Fuzi, H. Ramadhan.. 2020. "Metode Activity Relationship Chart (ARC) Pada Bengkel Nusantara Depok”. Jurnal Industrial Engineering Vol.1 No.2 hal: 20-22.

[4] W.I. Rahmadani. 2020. "Perancangan Ulang Tata Letak Gudang Menggunakan Metode Konvensional, Corelap Dan Simulasi Promodel”. Jurnal Optimasi Teknik Industri Vol.02 No.01 hal: 13-18.

[5] Andy, Dwiky Alamsyah. Suhartini. 2021. "Usulan Rancangan Tata Letak Fasilitas Proses Replating Kapal Dengan Menggunakan Metode ARC Dan ARD”. Seminar Nasional Teknologi Industri Berkelanjutan 1. hal: 65-71. 